\title{
The Key Principles of Process Manager Motivation in Production and Administration Processes in an Industrial Enterprise
}

\section{- Chromjaková Felicita}

\begin{abstract}
The basic premise of sustainable development is that companies should completely re-evaluate their enterprise work logic and process organization. Most of the necessary changes concern employee stimulation and motivation. If we are truly interested in improving business results and the effectiveness of business processes - there would be no progress otherwise - we have to strive to break down the barriers between company management (leadership) and employees in order to establish effective relationships between firms and customers. This paper presents research results of process manager activities in modern industrial enterprises, connected with a methodology proposal for the systematically-oriented process manager motivation of employees in accordance with the increased competitiveness of production and administration processes. It also presents an effective methodology of how to increase the positive effects of welldefined employee motivations from the process manager's perspective. The core benefit of this methodology lies in the design of a systematic approach to the motivation process from the process manager side, allowing for radical performance improvement via production and administrative processes and the increased competitiveness of enterprise processes.
\end{abstract}

Keywords: process manager, efficiency, effectiveness, motivation

JEL Classification: 0330

\section{GOALS OF THE CONTRIBUTION}

Firstly it is necessary clearly formulate the goals of this contribution from scientific and practical point of view. Based on the analysis of selected parameters of production and administrative processes in industrial companies to identify the systematic oriented key process manager activities that lead to unambiguous and continuous growth of process performance in industrial enterprise. Next to formulate basic pillars of motivation criterions connected with reporting analytics; both are leading to the effective continuous improvement of enterprise processes. Scientific contribution of this paper lies in development of new model of measurable motivation metrics enabled the positive reaction on the stabile performance improvement.

Practical effects of this contribution are in the proposal of systematic ability of process manager better to coordinate production and administration processes as a whole through set of effective and measurable process steps oriented on the competitiveness improvement.

Change management has been a major focus of process excellence teams for a number of years recently. Many of our employees will never honestly share the ideas of our company unless they are convinced of the validity of the new processes initiating before it even began. People are not 
stressed for the reason of having too many changes in organizations, but for the reason of the way the change is made. The process might increase productivity on a paper. However, what about the existing pressure on our staff?

Leadership is not a sort of manipulation - it depends mainly on integrity and it has an extraordinary power. Leadership, as it is, can make the difference between success and failure in anything you do for yourself or any group you belong to. Regardless of your own abilities, there are many important goals that you cannot attain without the help of others. Leadership is the changing of a man's vision to higher sights, the raising of a man's performance to a higher standard, the building of a man's personality beyond its normal limitations.

Enterprises will seek to map their processes on a daily basis; they derive their operational and strategic plans from this strategy. Fulfilment of target parameters defined by enterprise outputs is a question of a good corporate alchemy that takes into account available corporate DNA and customer's DNA.

Increasing the efficiency of production and administrative processes in a company requires certain skills, abilities, knowledge and behaviours. Many companies are looking for a comprehensive alternative of increasing the efficiency of their own processes, striving for minimum effort to deal with complicated market opportunities.

\section{LITERATURE REVIEW}

We consider the case in which all workers can be trained on all tasks, the workforce is a resource that determines the capacity and a complete forecasting of demand is not available (Olivella $\&$ Nembhard, 2015). We find the strongest effect for employees with the lowest levels of firm tenure. This is a quite novel result as this group should face the lowest separation costs, for instance, due to the accumulation of firm-specific human capital. Hence, intra-firm trainings are an important retention device, especially for newly or recently hired employees. Furthermore, a short-term decrease in absenteeism indicates a temporary, reciprocal reaction by employees (Kampkotter \& Marggraf, 2015).

A typical target firm improves production efficiency in the 3 years after intervention, with stronger improvements in business strategy-oriented interventions. Plants sold after intervention improve productivity significantly under new ownership, suggesting that capital redeployment is an important channel for value creation. Employees of target firms experience stagnation in work hours and wages despite an increase in labor productivity (Brav, Jiang, \& Kim, 2015). The results identify four organizational climate dimensions that focus on HR issues and work environments. Based on the suggestions of the competing values framework and also on the literature concerning studies of societal culture, we labeled these climate dimensions as: 1) collaboration; 2) competition; 3) control; and 4) family-orientation. These dimensions are seen to offer a path for future research on organizational climate and human resource management, and how employee's perceptions of the HR policies, practices and procedures may influence the efficacy of the HR function. Implications for studying these phenomena across different societies are addressed (Dastmaichian, McNeil, Blyton, Bacon, \& Blunsdon, 2015). 
Despite SMEs having limited resources, the results show a significant section of SMEs to be innovative and entrepreneurial organizations, embracing advancements in employment relations regarding employee discretion, training, participative working arrangements, and/or job security. Moreover, results indicate that WFPs have the potential to assist SMEs in responding to periods of constrained demand. Flexi time and job sharing are associated with low permanentemployee redundancies. Training, job security, and family-friendly practices relate to low absenteeism with reductions of up to six annual days per worker. Job security and profit-related pay are associated with high financial turnover. Staff pay-freeze links with high financial turnover, but to the detriment of redundancies and absenteeism, whereas management pay-cuts or management pay-freeze relate to low financial turnover. On a cautionary note, spending cuts, often enforced by policymakers, may be of limited benefit to SMEs, and thus other approaches would appear more fruitful (Whyman, \& Petrescu, 2015).The results suggest that middle managers' disposition towards proactiveness and innovativeness is positively related to their creative performance, and their internal bonding networks and upper management networks are found to strengthen the effects of entrepreneurial orientation on creative performance. However, middle managers' external bridging networks are found to have an inverted U-shaped curvilinear relationship with their creative performance, and to weaken the effect of entrepreneurial orientation on creative performance. These findings give echo to the interactions perspective of creativity, implying that middle managers should manage their social networks more carefully, as social interaction with network actors may either facilitate or inhibit their creativity at work (Chen, Chang, \& Chang, 2015).

Ergonomics interventions have the potential to improve operational performance and employee well-being. When the organization used ergonomics to promote performance and well-being equally, and at a high level, employees reported less work-related pain. A larger discrepancy between measures of operational performance and employee well-being was associated with increased reports of work-related pain. The direction of this discrepancy was not significantly related to work-related pain, such that it didn't matter which facet was valued more (Hoffmeister, Gibbons, Schwatka, \& Rosecrance, 2015).Our empirical findings support a positive relationship between three measures of workplace performance (financial performance, employees productivity and product or service quality) and average employee trust at both points in time. Moreover, this relationship holds when we jointly model average employee trust and firm performance in an instrumental variable framework in order to take into account the potential endogeneity of employee trust. Our findings suggest that restricting paid overtime and access to training potentially erode employee trust. In addition, we find that job or work reorganization experienced at either the employee or organization level is associated with lower employee trust (Brown, Gray, McHardy, \& Taylor, 2015).

Employees who reported having experienced work environment problems but also fair leadership, good social climate, role clarity and control of decision had significantly lower levels of production loss, whereas employees who reported inequality and high decision demands reported significantly higher levels of production loss. Never or seldom experiencing fair leadership, role clarity, equality, decision demands and good social climate increase the risk of production loss due to work environment problems, compared to those who experience these circumstances 
frequently, always or most of the time. Several psychosocial work factors are identified as factors associated with a reduced risk of production losses among employees despite the nature of the work environment problem. Knowledge of these factors may be important not only to reduce employee ill-health and the corresponding health-related production loss, but also reduce immediate production loss due to work environment-related problems (Karlsson, Hagberg, \& Bergstrom, 2015).

Although various studies have investigated the changes in control systems due to the implementation of lean production, only a few studies have explored the effects of the remaining traditional controls on lean implementations. The new concept of control may co-exist with the traditional concept, but particularly at their interfaces, tensions may arise (Tillema, \& Steen, 2015).

\section{RESEARCH DESIGN AND METHODOLOGY}

Based on the latest knowledge in the area of process manager motivation in industrial companies, core questions of research reflect the need to identify absolutely important milestones in the current practice of process manager's oriented on the real absenteeism of adequate measurable metrics and effective motivation schemas in the production and administration teams. Key hypothesis of research methodology are based on the following knowledge:

- we have a clear definition of success or failure in our company processes - there is a set of measurable metrics oriented only on production technologies performance

- there is a minimum of the most simple form of teamwork on each workplace - motivation for improving process performance is very complicated in according to the flexibility in real time and by specific daily conditions

- each process or activity has its own manager/leader with his/her own competences and responsibilities

The knowledge of process values and process costs can also determine a key model for the organization and management of innovation processes, especially when striving to achieve the desired effects of innovative plans and projects, improving manufacturing and administrative processes. The philosophy of the model lies in the cross correlation effects of inputs and outputs multiple business units involved in creation of a higher added value in terms of business processes and customers.

Within the course of individual company interviews, the following question was raised: "What do you consider as an added value in the field of analysis of your production and administration processes from the process manager motivation point of view?” By this form of survey covered 150 medium industrial companies from Czech Republic (automotive 40\% (60 companies), engineering 30\% (45 companies), plastic industry 20\% (30 companies), chemical industry 10\% (15 companies)). The answers can be summarized in the following conclusions:

- a clearly defined structure of the input information in the field of process management (78\% respondents) 
- the possibility of comparing partial input parameters from different departments of the company with links to find mutual correlations between parameters with regard to the interpretation of the output parameters related to the input parameters ( $88 \%$ respondents)

- the possibility of making professional decisions on various alternative process solutions with regard to knowledge of the real input and output parameters of selected processes $(46 \%$ respondents)

- possible flexibility in combination with quantified variables with respect to their setting in the processes according to predetermined parameters (65\% respondents)

- prompt information about the reality of enterprise processes (98\% respondents)

- a clear understanding of the data used in selected reports, analyses by all process managers and employees ( $74 \%$ respondents)

From these partial conclusions, we have obtained the important result that the given type of input analysis is useful for the relevant and process oriented quantification of input and output parameters, and for defining the scope and content of structured dates which have their justification for this type of analysis.

The preliminary analytical investigation has shown that it is necessary to link the management of key performance indicators, productivity and efficiency with key non-financial metrics into a single comprehensive and compact defined unit, which gives us the possibility of managing the core processes in a flexible way, supporting processes and organisational enterprise processes as a whole. Therefore, we focus on the fundamental orientation of production processes together with the related administrative and management processes.

Company practice now urgently seeks an unequivocal answer to the following question: "How can way effectively interconnect enterprise process management in the form of two mutual connected schemas: a process map and organizational structure?" This is a crucial question of our time as these are to become the models of optimization of planning, management and process parameters improvement.

It is evident that although the company has the best organizational and process structures, on the schema it looks perfect, the practice is different. Both schemas are totally non-functional or have a number of procedural and organizational conflicts.

In our research methodology, we have assumed that the ideal connection is represented purely through the relevant process structure of administrative and production processes with the key emphasis on clear and measurable identification of process owners - core process responsible and process competitive ones who have clearly declared their own responsibility area and relevant and measurable process goals. Each process owner should have adequately defined his/her own position regarding the right job area that is connected through the qualification and responsibility matrix with other jobs in a selected production or administration process. It is absolutely necessary to clearly define the relevant combination of process and organizational structure, the goal of both structures according to the relevant process job definition and the goal to minimize the potential risk of operational and strategic conflicts during the planning, organizing and realization processes for better efficiency and total enterprise production performance. 


\subsection{Theoretical Framework of Model Proposal}

The requirement is to develop a model for the planning and control of selected parameters of production and supporting processes with the goal to find and set optimal, effective and productive production system - an optimised complex manufacturing system - it should have the following theoretical backgrounds in the global and strong competitive economy:

- the key process parameters of production and supporting processes are known in their complexity, which helps to develop a strategic and operative goal orientation of the whole production process

- business processes are clearly structured so that it can be used for the planning, management and improvement of the methodology for process optimisation depending on the type of processes and products

- key indicators of globally operating industrial companies are known; these will be a part of the proposed methodology with the goal of a simple benchmarking and management of globally operating enterprise

- it is possible to define the ranges of acceptable values for defined process parameters so that when these are achieved, there is no threat to production and process site of value chain - value added process - in industrial enterprise from the stable performance, productivity and efficiency perspective

The key holder of process management is the personality of a process engineer and his team. Their common goal is to ensure the optimal implementation of key process activities changes and features in order to achieve desired results with a preference of efficient and productive value stream within production process. Complexly motivation model consists from 6 key groups of motivation metrics, integrated in so-called "Innovation capacity" circle (see fig. 1). Each process manager should own each one element in his or her own personality, because it is crucial to make motivation in production processes complexly with strong and clear orientation on the full satisfaction with optimal processes performance by himself and by his or her team of workers. Each one position in this circle indicates the core knowledge or group of professional skills of process manager that is useful for effective motivation processes.

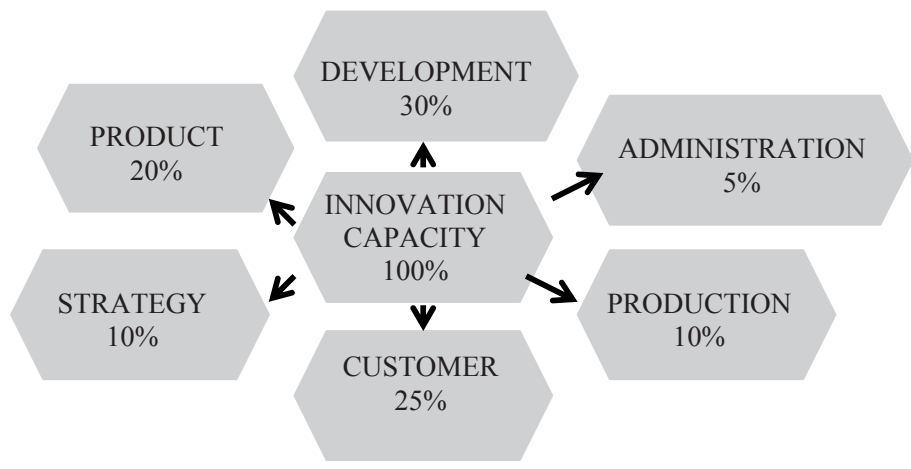

Fig. 1 - Core motivation pillars by process engineer about internal production/administration processes (author) 


\subsection{Proposal of system of value for personality of process manager}

Therefore, we have formulated the following paradigms, forming a system of values for personality of process managers:

1. Great knowledge of themselves, own job description and orientation, qualifications and qualities of a process manager

2. Right definition of personal, process and product goals

3. Ability to manage themselves and their colleagues

4. Ability to see the process in context and in real time

5. Knowledge of processes and related products with an emphasis on process owner

6. Ability and willingness to share and flexibly deal with the situation arising from the process in real time

7. Ability to spread their own experiences and pass them on to others to enhance the knowledge of all as one team

8. Having their own system of process development - schema - which corresponds with the company goals and innovative firm potential

9. Ability to provide own colleagues with ideas and simultaneously to make them real through new projects

In each company we can use this system for regular audit of process manager results achieved in production and administration processes. Next this system can be very effectively utilized for construction of measurable motivation metrics as a delegated mechanism on team workers, masters and other leaders in the mentioned processes. Based on this system they can effectively influence the real information and material flow by their own workplaces with the goal to stabilise optimal process performance and to initiate each day processes connected with the elimination of failures in realised processes with direct connection on the continuous improvement processes and higher competitiveness of processes.

\section{RESULTS AND DISCUSSION}

The basis of process engineers' motivation is their own confidence and confidence in their workers / team workers. According to this fact, we formulated the following criterions for adequate motivation of a process manager profession: 
Tab. 1 - Motivation criterions for process managers and their workers

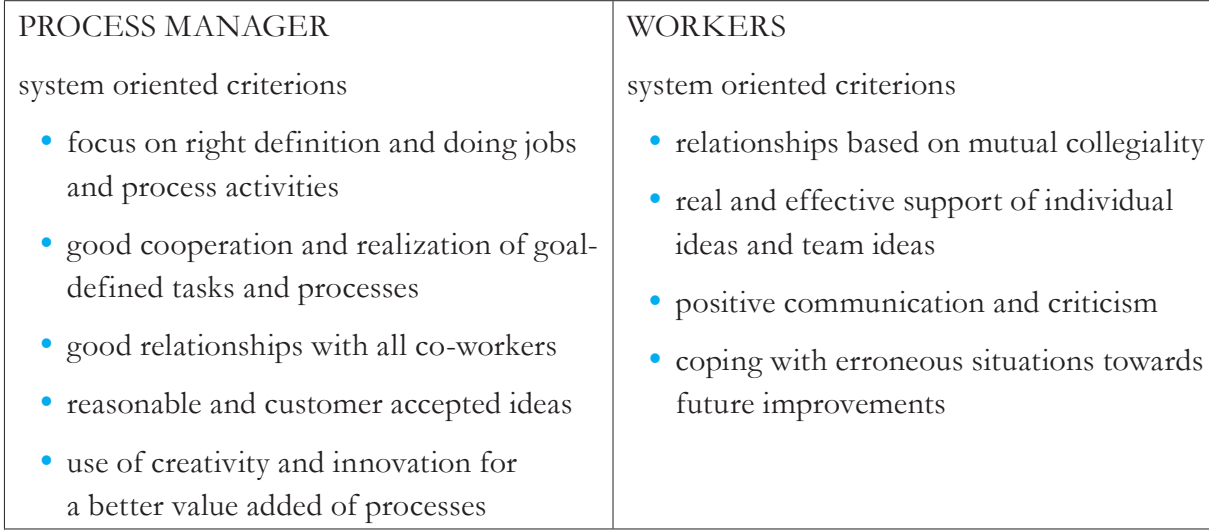

Important motivation criterions from process manager

process oriented criterions

1. Only few things can help a person more than to make him responsible and let him know that we trust him - exactly defined responsibility on your workers

2. If we are thinking that the problem is outside of us, then it is this single idea itself- the problem for us - managed and effective oriented communication process between workers and process management

Motivation criterions oriented on effective team work

Self-confidence - Trust in relationships - Trust in the company - Trust in people

The formulation of a proposed process manager motivation methodology comes out from the following questions and answers (more than 150 respondents - process managers in industrial companies).

The core content of the questions was the focus on the complexity, variability and adequate process management towards the elimination of process errors. We have also emphasized that the system-oriented process management is directly dependent on geographical location of the company, company size, defined process layout and a specific form of process planning - management - control of production and supporting processes.

Selected questions from the questionnaire:

- How do you ensure that the process is getting stable and satisfies the requirements of internal and external customers in present form?

Paradigm: as a process of interconnected activities, specifically focused on goal achievement $(79 \%)$, as a process of optimal combination of process and organizational matrix structure $(21 \%)$

- How do you ensure the quality and completeness of the process and process steps that are necessary for a flexible order when handling the process? 
Paradigm: the quality of the process and process steps is determined by lean thinking philosophy strongly connected with the own man discipline (62\%), compliance with the agreed rules and events $(17 \%)$, tightening of things to the successful end $(21 \%)$

- How do you secure the process substitutability?

Paradigm: the right definition of a job done (42\%), simultaneously addressing the selected key tasks through more subordinate employees to a process manager $(58 \%)$

- How quickly and in qualified way can you do the process change without the risk of threat by other processes?

Paradigm: a strict adherence of pulling and pushing principles by tasks fulfilment (85\%), flexible tasks fulfilment by customer preferences (15\%)

- Are you able to develop and set up an infrastructure that will allow us to work productively?

Paradigm: the throughput of a value stream process is in direct correlation with the defined process goal, process driver identification and management of limiting factors in accordance with achievement of defined goals (74\%), manufacturing technology is not a dogma, it is a space that uses the process manager for the maximal effective utilisation of all available potentials in order to meet the customer requirements on time and in a high quality $(26 \%)$

There is no independent department for process management in our companies. All individual sub-processes and activities implemented in the processes are divided into the areas of responsibility within several departments, e.g. production department has its own person responsible for it but the process department does not exist - its role and indispensability for the management of production is indisputable.

The main reason for that is that many companies are struggling with the absence of limits for the area of standardization of business processes, especially in the field of flexible process concepts.

The key motivation stimuli of a process manager identified by testing procedures and verifying of proposed model include acceptable values and define min and max values for stabile motivation process in short time horizon - example for 1 month motivation goal:

- reduction of total production costs of completed processes and products (min $0,5 \%$, max $2 \%)$

- elimination of total product costs in defined and controlled value stream (min 0,2\%, max $1 \%)$

- reduction of working capital in actual value stream (min $0,2 \%, \max 1 \%$ )

- increasing the turnaround of assets, integrated as a fixed component in manufacturing and supporting administrative processes $(\min 0,1 \%, \max 0,3 \%$ )

- assets and liabilities priorities with regard to their added value in complex value chain (min 1 priority - may be one for assets/or one for liabilities, max 2 priorities per month) 
- flexibility of workers for other job realisation ( $\min -1$ worker for 3 jobs, max -1 worker for 5 jobs)

- increasing efficiency and effectiveness of the operational portfolio available (technology, jobs, workplaces, information transfer and actualisation in real time) (min 5\%, max 12\% effectiveness)

Tab. 2 - Example of reporting analytics - recommendation for statement of motivation system oriented criterions by workers from the process manager site

\begin{tabular}{|c|c|c|c|c|c|}
\hline \multicolumn{7}{|c|}{ Calculation of the planned cycle time } \\
\hline Tact time & 5,8 & $\mathrm{sec} / \mathrm{pc}$ & & & \\
\hline OEE & $76,0 \%$ & & Planned cycle time & 3,1 & $\mathrm{sec} / \mathrm{pc}$ \\
\hline Cycle process time & 4 & $\mathrm{sec} / \mathrm{pc}$ & OEE cycle process time & 5,2 & $\mathrm{sec} / \mathrm{pc}$ \\
\hline
\end{tabular}

\subsection{Proposal of „Reporting analytics structure“ - key motivation tool for process management}

1. Development evtl. updating of database for collecting, sorting and evaluation of process dates

- Core database: product characteristics database, database of production process parameters, related supporting processes database for production planning and scheduling, supplier database, customer requirement database

- supporting databases: product/process specification database, production processes standards and workplace characteristics database, product material databases, external contractors database, personnel database, qualification matrix database of production workers, improvement processes/innovations database

2. Setting evtl. recodification of the specified dates about process parameters in real time

- process parameters classified according to the type: key process information (e.g. development of a production plan), supporting process information (e.g. evidence of orders received), organizational process information (e.g. time and volume schedule of working operations by selected workplace)

3. A clear visualization of dates and databases for efficient processing dates by given criteria for the area of performance and efficiency (example see fig. 2 - monitoring of real daily situation by workplace, important identification for process manager about efficiency of worker) 


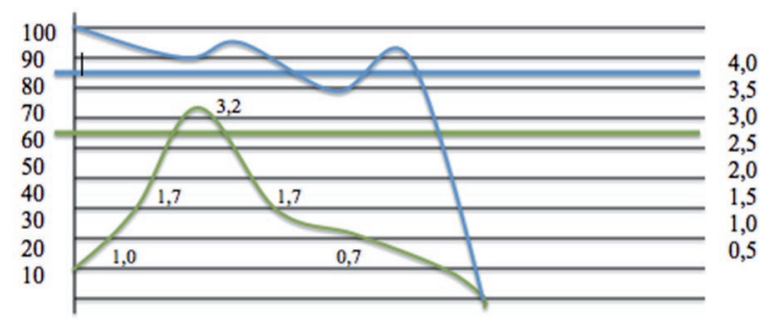

Fig. 2 - Productivity (green line) versus re-work (blue line) (author)

4. Making sure that there are reporting analytics - setting specific types of outputs from databases that will be regularly updated, evaluated, presented, and will be operationally useful for meetings, decision-making and management processes purposes. One part of the criteria of reporting analytics is the secured variability and correlation of available dates

5. Setting the algorithm for selected process situations enabling a flexible use of available dates for planning, decision-making and control of production and supporting administration processes

6. Setting the responsibility for management and updating available databases by single drivers of process positions, resp. process owners (example table 3 - each process manager define adequate parameters according to the selected job position, workers, production flow)

- core responsibility - IT manager in collaboration with owners of key processes (purchase, production planning - scheduling - organization, logistics)

- assigned responsibilities for supporting processes - a coordinator elected by the director of IT in collaboration with owners of supporting processes (quality, human resources, maintenance, etc.).

Tab. 3 - Example of algorithm setting for selected type of a process situation - identification of motivation parameters for workers as a basis for financial and non-financial motivation of workers

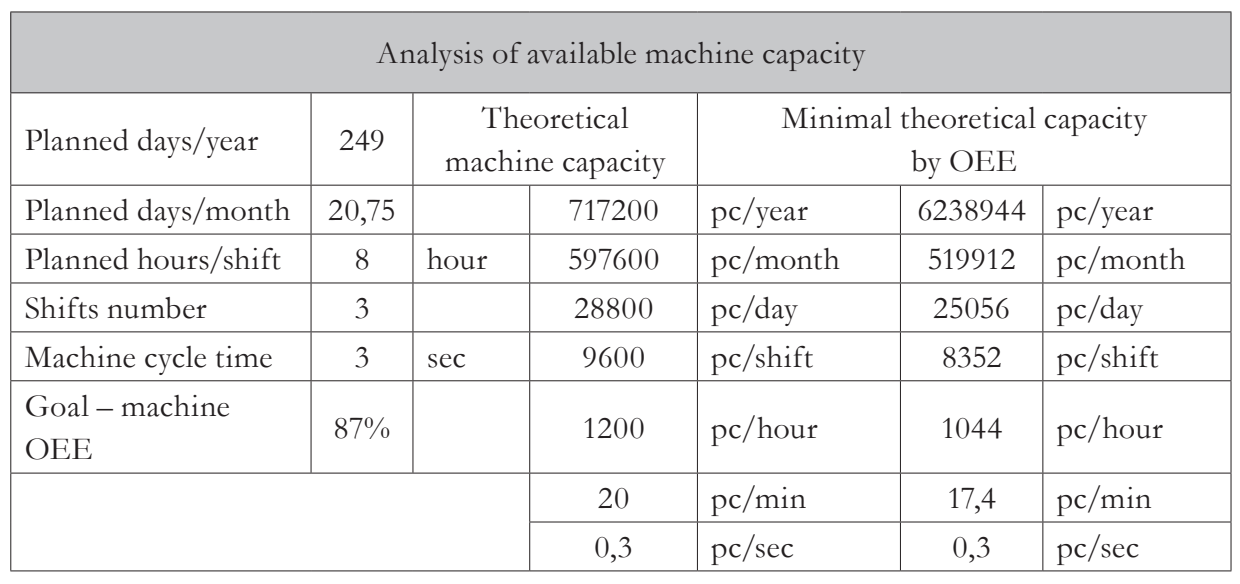


Based on the quantification of the above-mentioned key areas in our model, we calculate the overall performance ability of process management system in the following structure:

- index of enterprise cycle time for realization of enterprise process

- index of effectiveness of cycle time (processing time versus unproductive process time)

- index of tact time of process steps in the complex process chain

- index of inventory by the process tasks (throughput x cycle time)

In this context, we can state that the research focused on finding the root causes of deviations in the continuous flow of process activities at the stage of realization in response to the process analysis and planning. According to our study, there are three possible types of basic deviations:

- the level of process buffer (buffer of administrative tasks at production workplaces)

- the ability of process to block the next / previous process (with regard to setting the process and regulation of continuous process flow)

- the absence of process input / output (ill-defined inputs / outputs at the planning stage and a subsequent bad fulfilment of planned inputs / outputs by preparation request before processes

The key paradigm at this moment can be considered company employees responsible for the process analysis and process mapping. It is very important at this stage that they have standardized the workflow to be able to adequately adjust the planned processes and to regulate the flowed processes. Subsequently, the core process parameters were defined - as core motivation tools in the practice of a process manager:

- process classification (main, supporting, organizational)

- ability to simplify the process (process layout)

- possibility of increasing the volume of a classified process (process flexibility upwards due to an increase in capacity need)

- process characteristics (continuous, repetitive, intermittent)

- setting a classified process (possibility of defining the size of loss, stochastic process)

- process innovation (in relation to the product and process)

The unambiguous conclusion of the proposed methodology is that if the company has described its own processes with regard to the quality of the process and products, then all four following parameters achieved the optimal result:

- process attractiveness

- process uniqueness

- maximal process capacity

- process repeatability 
The problem arises at the moment when we have not assigned the responsible persons for process goals achievement. In this case, we are unable to predict the future of process development in strategic as well as in operational horizon. For this reason, a clear definition of the key performance indicators is considered the most important one. It should be a part of clear dimension of the output process units, stating a maximum possible percentage of poor quality in the process and costs of the process profitability.

In this context, we emphasize the need of process managers' focus on lean thinking and other members of process teams. Next, it is the focus on the quantification of the following parameters:

- value of process output

- setting an optimal value stream

- analysis of a process flow

- possibility of using push and pull principles in order to achieve a continuous throughput

- quality of process realization

In this methodology, the process steps and their definition from the lean thinking point of view was not priority. It was about the idea how it is possible to use the principles of lean thinking for adjustment of process variability in the planning stage and how to use this knowledge for motivation of employees from the process manager's perspective. By testing, the attention was paid to identification of loss-making operations and activities as well as to the irregularity in the process behaviour. The greater part of companies, being tested by this methodology $(87 \%)$, confirms that they pay higher attention to achievement of financial process outputs. Then, they focus $(13 \%)$ on the problem regarding achievement of process flow analysis, i.e. the qualified feedback from process reality and a process manager is absent in most cases, which could be the adequate basis for improvement of process steps in the future.

\section{CONCLUSION}

A substantial contribution of the proposed methodology is that we understand the motivation process from the process manager's perspective as a comprehensive "supply chain" of "requirements chain". While the first system primarily concentrates on keeping the powerful inputs supply system, the second system is primarily dependent on the flow principle setting. The study confirmed that many companies have a profound deficit in prediction of continuous flow development. The main reason for this is probably the incompetence of flexible order management.

In the methodology, the following core questions were answered:

- how we can plan and organize the flow and realization process of orders

- how we have developed the potential for process improvement

- if we are able to identify and meaningfully exploit the competitive advantage of each production process

- how we have set up a mechanism for strategic orientation of production processes and supporting processes 
- if we are able to manage core competencies of a process, accepting the current reality and requirements regarding effective process improvement from the process manager's perspective - optimal coordination of own employees

\subsection{Highlight the practical application of results and conclusions for practical use}

The verification of proposed methodology in 150 industrial companies showed a clear interest in better specification of individual approaches in the area of process improvement and process innovations. There is a great importance of paying attention to the interconnection of two key process areas - manufacturing and administration areas - with the goal to increase their added value for internal and external customers.

Special were tested proposed criterions for process manager and workers, results achieved by this stage demonstrated the need for such actions, which introduced a "system" in the process manager motivation tools. Several process managers confirmed the relevance and practical application of the proposed value system, based on the process goals and combined with the approach "man-machine" as an effective way for workers productivity increasing on a daily basis.

Integration of "reporting analytics" in this model is dependent from the enterprise information systems, although there is a confirmed fact that it is necessary to have a minimal itinerary of process manager reports, enabling the flexible motivation of employees, depending on your daily performance.

This paper is one of contribution to the RVO project "Modelling of effective production and administration processes parameters in industrial companies based on concept Industry 4.0", realized by Department of Entrepreneurship and Industrial Engineering, Faculty of Management and Economics, Tomas Bata University in Zlin.

\section{References}

1. A. Seetharaman, John Rudolph Raj, \& Saravanan Arumugam Seetharaman. (2015). The Implementation of Total Quality Management in Controlling the Cost of Manufacturing. Journal of Distribution Science, 13(8), 27-40. doi:10.15722/jds.13.8.201508.27

2. Bagherpour, M., \& Noori, S. (2011). Cost management system within a production environment: a performance-based approach. Proceedings of the Institution of Mechanical Engineers, Part B: Journal of Engineering Manufacture, 226(1), 145-153. doi:10.1177/095440541 1404303

3. Bertolotti, F., Mattarelli, E., Vignoli, M., \& Macrì, D. M. (2015). Exploring the relationship between multiple team membership and team performance: The role of social networks and collaborative technology. Research Policy, 44(4), 911-924. doi:10.1016/j.respol.2015.01.019

4. Bonavia, T., \& Marin-Garcia, J. A. (2011). Integrating human resource management into lean production and their impact on organizational performance. International Journal of Manpower, 32(8), 923-938. doi:10.1108/01437721111181679

5. Brav, A., Jiang, W., \& Kim, H. (2015). The Real Effects of Hedge Fund Activism: Productivity, Asset Allocation, and Labor Outcomes. Review of Financial Studies, 28(10), 2723-2769. doi:10.1093/rfs/hhv037 
6. Brown, S., Gray, D., McHardy, J., \& Taylor, K. (2015). Employee trust and workplace performance. Journal of Economic Behavior \& Organization, 116, 361-378. doi:10.1016/ j.jebo.2015.05.001

7. Charalambous, G., Fletcher, S., \& Webb, P. (2015). Identifying the key organisational human factors for introducing human-robot collaboration in industry: an exploratory study. In: International Journal of Advanced Manufacturing Technology, 81(9-12), 2143-2155

8. Chen, M.-H., Chang, Y.-Y., \& Chang, Y.-C. (2015). Entrepreneurial Orientation, Social Networks, and Creative Performance: Middle Managers as Corporate Entrepreneurs. Creativity and Innovation Management, 24(3), 493-507. doi:10.1111/caim.12108

9. Dastmalchian, A., McNeil, N., Blyton, P., Bacon, N., Blunsdon, B., Kabasakal, H., ... Steinke, C. (2015). Organisational climate and human resources: exploring a new construct in a cross-national context. Asia Pacific Journal of Human Resources, 53(4), 397-414. doi:10.1111/1744-7941.12081

10. Fullerton, R. R., Kennedy, F. A., \& Widener, S. K. (2013). Management accounting and control practices in a lean manufacturing environment. Accounting, Organizations and Society, 38(1), 50-71. doi:10.1016/j.aos.2012.10.001

11. Hoffmeister, K., Gibbons, A., Schwatka, N., \& Rosecrance, J. (2015). Ergonomics Climate Assessment: A measure of operational performance and employee well-being. Applied Ergonomics, 50, 160-169. doi:10.1016/j.apergo.2015.03.011

12. Kampkötter, P., \& Marggraf, K. (2015). Do employees reciprocate to intra-firm trainings? An analysis of absenteeism and turnover rates. In: International Journal of Human Resource Management, 26(22). 2888-2907

13. Klingenberg, B., Timberlake, R., Geurts, T. G., \& Brown, R. J. (2013). The relationship of operational innovation and financial performance-A critical perspective. International Journal of Production Economics, 142(2), 317-323. doi:10.1016/j.ijpe.2012.12.001

14. Lohela-Karlsson, M., Hagberg, J., \& Bergström, G. (2014). Production loss among employees perceiving work environment problems. International Archives of Occupational and Environmental Health, 88(6), 769-777. doi:10.1007/s00420-014-1003-0

15. McGuirk, H., Lenihan, H., \& Hart, M. (2015). Measuring the impact of innovative human capital on small firms' propensity to innovate. Research Policy, 44(4), 965-976. doi:10.1016/ j.respol.2014.11.008

16. Michaelis, B., Wagner, J. D., \& Schweizer, L. (2015). Knowledge as a key in the relationship between high-performance work systems and workforce productivity. Journal of Business Research, 68(5), 1035-1044. doi:10.1016/j.jbusres.2014.10.005

17. Nigatu, Y. T., van de Ven, H. A., van der Klink, J. J. L., Brouwer, S., Reijneveld, S. A., \& Bültmann, U. (2016). Overweight, obesity and work functioning: The role of working-time arrangements. Applied Ergonomics, 52, 128-134. doi:10.1016/j.apergo.2015.07.016

18. Olivella, J., \& Nembhard, D. (2016). Calibrating cross-training to meet demand mix variation and employee absence. European Journal of Operational Research, 248(2), 462-472. doi:10.1016/j.ejor.2015.07.03 
19. Oswald, A. J., Proto, E., \& Sgroi, D. (2015). Happiness and Productivity. Journal of Labor Economics, 33(4), 789-822. doi:10.1086/681096

20. Sijborn, R. B., Janssen,O., van Yperen, N.W.(2015). Leaders'reactions to radical creative ideas voiced by employees: The role of leaders'achievement goals. In: Gedrag \& Organisatie, 28(2), 154-173

21. Sikora, D. M., Ferris, G. R., \& Van Iddekinge, C. H. (2015). Line manager implementation perceptions as a mediator of relations between high-performance work practices and employee outcomes. Journal of Applied Psychology, 100(6), 1908-1918. doi:10.1037/ap10000024

22. Tillema, S., \& van der Steen, M. (2015). Co-existing concepts of management control. Management Accounting Research, 27, 67-83. doi:10.1016/j.mar.2015.01.002

23. Whyman, P. B., \& Petrescu, A. I. (2013). Workplace Flexibility Practices in SMEs: Relationship with Performance via Redundancies, Absenteeism, and Financial Turnover. Journal of Small Business Management, 53(4), 1097-1126. doi:10.1111/jsbm.12092

\section{Contact information}

Prof. Dr.-Ing. Felicita Chromjaková

Tomas Bata University in Zlin

Faculty of Management and Economics

Department of Industrial Engineering and Information Systems

Mostni 5139, 76001 Zlin

Crech Republic

E-mail:chromjakova@fame.utb.cz. 